\section{Factors related to the efficacy of radiofrequency ablation for benign thyroid nodules}

\author{
Jung Hwan Baek
}

Department of Radiology and Research Institute of Radiology, Asan Medical Center, University of Ulsan College of Medicine, Seoul, Korea

We read with great interest the article published by Ahn et al. entitled "Radiofrequency ablation of benign thyroid nodules: evaluation of the treatment efficacy using ultrasonography" in Ultrasonography [1]. The authors evaluated the relationships of internal (ultrasonographic [US] findings) and external factors (treatment-related findings) with the treatment efficacy of radiofrequency ablation (RFA) for treating benign thyroid nodules. Their study achieved an acceptable volume reduction ratio (VRR; $74.3 \%$ ) and $90.9 \%$ therapeutic success at a 1-year follow-up. In addition, ill-defined margins (an internal factor) showed a tendency to be associated with a low VRR during follow-up examinations; however, no external factors were related to the efficacy. This is the first study to assess the detailed US features of nodules as part of an evaluation of the factors related to efficacy. Recently, marginal regrowth has come to be regarded as an important cause of recurrence after RFA; therefore, the findings of this study are important for achieving better results.

We appreciated that the authors showed valuable results for predicting the treatment efficacy of thyroid RFA by evaluating internal and external factors. Moreover, they followed the recommendations of the current Korean guidelines [2]. First, they enrolled their patients using standard inclusion criteria [2]. Second, they used standard techniques: local anesthesia, the transisthmic approach, and the moving-shot technique under US guidance [2]. Moreover, they used a thyroid-dedicated electrode (a straight-type, modified, internally cooled electrode). Third, they used a standard follow-up protocol. The use of a standard technique, devices, and protocols increased the value of this study. They also performed two separate biopsy sessions to confirm benignity [3].

Although their study followed the Korean guidelines, it had several limitations, including the fact that it was a retrospective study, had a small population, and included a short-term followup period. I agree with these limitations and I will address several points that should be considered to understand the results of their study [1]. First, I will address the measurement issue. Variation in measurements of nodule size is an important factor, especially in ill-defined nodules. Recently, Choi et al. [4] reported interobserver variations in thyroid nodule US measurements. They suggested that any differences smaller than $13.1 \%$ (volume) and $7.3 \%$ (diameter) should not be considered as real changes in size. Therefore, measurement variation in ill-defined nodules should be carefully addressed. Second, other studies have suggested that many extrinsic factors are related to efficacy or recurrence, such as operator experience, number of treatment sessions, tumor vascularity, and delivered energy; however, none of these factors showed significant associations in their study. In particular, the number of treatment sessions is a well-known factor related to efficacy, as shown by a randomized clinical trial [5]. In my opinion, the small number of patients in the non-therapeutic success group $(n=4)$ may

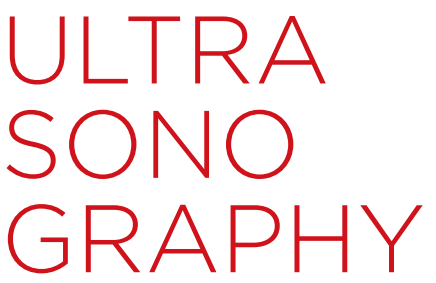

\section{LETTER}

https://doi.org/10.14366/usg.17034 pISSN: 2288-5919 • elSSN: 2288-5943 Ultrasonography 2017;36:385-386

Received: April 16, 2017 Accepted: May 17, 2017

Correspondence to: Jung Hwan Baek, MD, PhD, Department of Radiology and Research Institute of Radiology, Asan Medical Center, University of Ulsan College of Medicine, 88 Olympic-ro 43-gil, Songpa-gu, Seoul 05505, Korea

Tel. $+82-2-3010-4348$

Fax.+82-2-476-0090

E-mail: radbaek@naver.com

This is an Open Access article distributed under the terms of the Creative Commons Attribution NonCommercial License (http://creativecommons.org/ licenses/by-nc/3.0/) which permits unrestricted noncommercial use, distribution, and reproduction in any medium, provided the original work is properly cited.

Copyright @ 2017 Korean Society of Ultrasound in Medicine (KSUM)

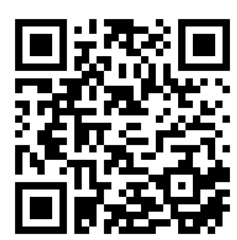

How to cite this article:

Baek JH. Factors related to the efficacy of radiofrequency ablation for benign thyroid nodules. Ultrasonography. 2017 Oct;36(4):385-386. 
have influenced the results.

In conclusion, the study of Ahn et al. [1] suggested factors related to the efficacy of thyroid RFA. They identified ill-defined margins as a poor prognostic factor. We suggest several points that should be considered by readers to help them understand the prognosis of benign thyroid nodules after RFA.

ORCID: Jung Hwan Baek: http://orcid.org/0000-0003-0480-4754

\section{Conflict of Interest}

No potential conflict of interest relevant to this article was reported.

\section{References}

1. Ahn HS, Kim SJ, Park SH, Seo M. Radiofrequency ablation of benign thyroid nodules: evaluation of the treatment efficacy using ultrasonography. Ultrasonography 2016;35:244-252.

2. Na DG, Lee JH, Jung SL, Kim JH, Sung JY, Shin JH, et al. Radiofrequency ablation of benign thyroid nodules and recurrent thyroid cancers: consensus statement and recommendations. Korean J Radiol 2012;13:117-125.

3. Russ $G$. Risk stratification of thyroid nodules on ultrasonography with the French TI-RADS: description and reflections. Ultrasonography 2016;35:25-38.

4. Choi YJ, Baek JH, Hong MJ, Lee JH. Inter-observer variation in ultrasound measurement of the volume and diameter of thyroid nodules. Korean J Radiol 2015;16:560-565.

5. Huh JY, Baek JH, Choi H, Kim JK, Lee JH. Symptomatic benign thyroid nodules: efficacy of additional radiofrequency ablation treatment session: prospective randomized study. Radiology 2012;263:909-916. 